\title{
Beliefs contributing to HIV-related stigma in African and Afro-Caribbean communities in the Netherlands
}

Citation for published version (APA):

Stutterheim, S., Bos, A., Kesteren, N. M. C., Shiripinda, I., Pryor, J. B., de Bruin, M., \& Schaalma, H. P. (2012). Beliefs contributing to HIV-related stigma in African and Afro-Caribbean communities in the Netherlands. Journal of Community \& Applied Social Psychology, 22(6), 470-484. https://doi.org/10.1002/casp.1129

Document status and date:

Published: 01/01/2012

DOI:

10.1002/casp.1129

Document Version:

Publisher's PDF, also known as Version of record

Document license:

Taverne

Please check the document version of this publication:

- A submitted manuscript is the version of the article upon submission and before peer-review. There can be important differences between the submitted version and the official published version of record.

People interested in the research are advised to contact the author for the final version of the publication, or visit the DOI to the publisher's website.

- The final author version and the galley proof are versions of the publication after peer review.

- The final published version features the final layout of the paper including the volume, issue and page numbers.

Link to publication

\footnotetext{
General rights rights.

- You may freely distribute the URL identifying the publication in the public portal. please follow below link for the End User Agreement:

www.umlib.nl/taverne-license

Take down policy

If you believe that this document breaches copyright please contact us at:

repository@maastrichtuniversity.nl

providing details and we will investigate your claim.
}

Copyright and moral rights for the publications made accessible in the public portal are retained by the authors and/or other copyright owners and it is a condition of accessing publications that users recognise and abide by the legal requirements associated with these

- Users may download and print one copy of any publication from the public portal for the purpose of private study or research.

- You may not further distribute the material or use it for any profit-making activity or commercial gain

If the publication is distributed under the terms of Article $25 \mathrm{fa}$ of the Dutch Copyright Act, indicated by the "Taverne" license above, 
Journal of Community \& Applied Social Psychology

J. Community Appl. Soc. Psychol., 22: 470-484 (2012)

Published online 25 November 2011 in Wiley Online Library

(wileyonlinelibrary.com) DOI: 10.1002/casp.1129

\title{
Beliefs Contributing to HIV-related Stigma in African and Afro-Caribbean Communities in the Netherlands
}

\author{
SARAH E. STUTTERHEIM ${ }^{1,2 *}$, ARJAN E. R. BOS ${ }^{1,2}$, NICOLE M. C. VAN KESTEREN ${ }^{3}$, \\ IRIS SHIRIPINDA ${ }^{4}$, JOHN B. PRYOR $^{5}$, MARIJN DE BRUIN $^{6}$ and HERMANP. SCHAALMA ${ }^{2}$ \\ ${ }^{1}$ School of Psychology, Open University of the Netherlands, Heerlen, the Netherlands \\ ${ }^{2}$ Department of Work and Social Psychology, Maastricht University, Maastricht, the Netherlands \\ ${ }^{3}$ TNO Quality of Life, Leiden, the Netherlands \\ ${ }^{4}$ STI AIDS the Netherlands, Amsterdam, the Netherlands \\ ${ }^{5}$ Department of Psychology, Illinois State University, Normal, IL, USA \\ ${ }^{6}$ Communication Science, Wageningen University, Wageningen, the Netherlands
}

\begin{abstract}
Thirty years after the first diagnosis, people living with HIV (PLWH) around the world continue to report stigmatizing experiences. In this study, beliefs contributing to HIV-related stigma in African and Afro-Caribbean diaspora communities and their cultural context were explored through semistructured interviews with HIV-positive $(N=42)$ and HIV-negative $(N=52)$ African, Antillean and Surinamese diaspora community members in the Netherlands. Beliefs that HIV is highly contagious, that HIV is a very severe disease, and that PLWH are personally responsible for acquiring their HIV infection were found to contribute to HIV-related stigma, as did the belief that PLWH are HIV-positive because they engaged in norm-violating behaviour such as promiscuity, commercial sex work, and, for Afro-Caribbean diaspora, also homosexuality. These beliefs were found to be exacerbated and perpetuated by cultural taboos on talking about HIV and sexuality. HIV-related stigma reduction interventions should focus on changing these beliefs and breaking cultural taboos on HIV and sexuality in a manner that is participatory and consistent with the current theory and empirical findings. Copyright $(\subset) 2011$ John Wiley \& Sons, Ltd.
\end{abstract}

Key words: HIV/AIDS; stigma; ethnic minorities; immigrants; community; beliefs; interventions

Thirty years after the first diagnosis, HIV remains a highly stigmatized condition. Globally, people living with HIV (PLWH) continue to report stigmatizing experiences such as avoidance, abandonment, exclusion, rejection and blaming (Malcolm et al., 1998; Nyblade, Pande, Mathur, MacQuarrie, \& Kidd, 2003; Stutterheim, Bos, Shiripinda, et al., 2011;

*Correspondence to: Sarah Stutterheim, School of Psychology, Open University of the Netherlands, PO Box 2960, 6401 DL, Heerlen, the Netherlands.

E-mail: sarah.stutterheim@ou.nl 
Stutterheim et al., 2009). The consequences of HIV-related stigma are substantial and include hampered HIV prevention, testing delays, poor treatment adherence, psychological distress in PLWH and disrupted social interactions (Bos, Kok, \& Dijker, 2001; Mills, 2006; Stutterheim et al., 2009; Vermeer, Bos, Mbwambo, Kaaya, \& Schaalma, 2009). HIV-related stigma is a complex process of devaluation whereby a person is considered to possess a discrediting attribute and is subsequently deemed flawed by others (Crocker, Major, \& Steele, 1998; Goffman, 1963; Jones et al., 1984). Stigma is embedded in community processes and reinforces existing social inequalities and previously defined boundaries between 'us' and 'them' (Campbell \& Deacon, 2006; Nyblade et al., 2003; Parker \& Aggleton, 2003).

Sub-Saharan Africa and the Caribbean have long had the highest HIV prevalence rates in the world (UNAIDS, 2008). The generalized epidemics in these countries have also yielded high prevalence rates within diaspora communities. In the Netherlands, non-Western migrants comprise one tenth of the Dutch population but one third of all HIV cases. Of that third, more than half originate from Sub-Saharan Africa and almost a third from the Caribbean. Not only are prevalence rates for HIV higher in these diaspora communities, so too is HIV-related stigma. In fact, high levels of stigmatization have been reported not only in Sub-Saharan Africa (Greeff et al., 2008; Kalichman \& Simbayi, 2004; Nyblade et al., 2003) and the Caribbean (Carr, 2004; Varas-Diaz, Serrano-Garcia, \& Toro-Alfonso, 2005) but also in these regions' diaspora communities (M. Anderson et al., 2008; Dodds, 2006; Gardezi et al., 2008; Shiripinda \& van Eerdewijk, 2008; Stutterheim, Bos, Shiripinda, et al., 2011). The fear of stigmatization and the degree to which stigmatization is experienced have also been reported to be substantially greater among black PLWH living in Europe than among white PLWH (Dodds, 2006; Erwin, Morgan, Britten, Gray, \& Peters, 2002). This may, at least in part, be because African and Afro-Caribbean diaspora are already socially marginalized and disadvantaged by racism, immigration processes and anti-asylum discourses, and experience barriers in accessing health and social services as well as employment (Dodds, 2006; Dodds et al., 2004; Shiripinda \& van Eerdewijk, 2008). As such, their HIV-related stigma is compounded by other socially stigmatized conditions, thus resulting in what is termed layered or multiple stigmatization (Brown, Macintyre, \& Trujillo, 2003; Deacon, 2006; Genberg et al., 2009; Reidpath \& Chan, 2005).

Research conducted in Europe and North America has shown that a number of beliefs can contribute to HIV-related stigma. The first concerns the contagiousness of HIV. When HIV is considered highly contagious, fear of PLWH and subsequent stigmatization is likely. The second belief pertains to the severity of HIV. When HIV is considered a very serious or fatal condition, fear and stigmatization often result. The third belief concerns responsibility. When PLWH are considered personally responsible for their infection, anger, a lack of compassion and stigmatization are likely. The fourth belief is that PLWH are HIV-positive because they engaged in norm-violating behaviour such as homosexuality, commercial sex work and intravenous drug use. This belief can also generate anger, a lack of compassion and stigmatization (Bos, Dijker, \& Koomen, 2007; Dijker \& Koomen, 2003; Herek, 1999). In short, when HIV is considered highly contagious and very severe, when PLWH are considered responsible for acquiring HIV, and when HIV is associated with norm-violating behaviours, stigmatization is most likely.

Given that previous research findings have demonstrated that African and Afro-Caribbean communities are disproportionately affected by HIV and HIV-related stigma (Dodds, 2006; Erwin et al., 2002; Shiripinda \& van Eerdewijk, 2008) and with the knowledge that HIV-related stigma is socially constructed and considered to vary from one culture to another 
and from one community to another (Deacon, 2006; Maman et al., 2009; Norman, Abreu, Candelaria, \& Sala, 2009; Pryor, Reeder, \& Landau, 1999), we believe that it is important to investigate whether the beliefs found to contribute to the stigmatization of European and North American PLWH are also held by Sub-Saharan African and Caribbean people living in Europe or North America. We also believe that it is important to understand the social and cultural context within which such beliefs exist. Consequently, the present study qualitatively explored which beliefs held by African, Dutch Antillean and Surinamese diaspora contribute to the stigmatization of PLWH in their communities and the cultural context of these beliefs. We considered it particularly important to explore these beliefs in these diaspora communities not only because they are disproportionately affected by the epidemic but also because there is a paucity of literature on HIV-related stigma in African and Afro-Caribbean diaspora communities. In fact, to our knowledge, no study has comprehensively explored the beliefs contributing to HIV-related stigma in African and Afro-Caribbean diaspora communities. A few studies have touched on HIV's association with death, immorality and promiscuity, and the fact that there is significant fear of contamination in these diaspora communities (Anderson et al., 2008; Burns, Imrie, Nazroo, Johnson, \& Fenton, 2007; Dodds et al., 2004; Gardezi et al., 2008), but none have explored the beliefs contributing to HIV-related stigma extensively.

\section{METHODS}

Following study approval by Maastricht University's Ethics Committee, members of African, Dutch Antillean and Surinamese communities were recruited for face-to-face, semi-structured interviews by a researcher (SS, IS, MB) or by one of 12 peer interviewers employed and trained by the researchers. The large number of peer interviewers was deemed necessary as recruitment for participation in similar research has previously proven to be difficult. Recruitment of participants was purposeful and occurred directly through interviewers or through announcements distributed by the Dutch HIV Association, Humanitas Foundation or HIV nurses working in Dutch hospitals. Interviews of approximately an hour were held in either English or Dutch in accordance with the participant's preference at a location deemed appropriate by the participant (usually the participant's home). Both HIV-positive and HIV-negative African, Dutch Antillean and Surinamese community members were included in the study as this allowed for triangulation across data sources. Once recruited, participants were given information regarding the study's purpose and procedure. Given the current debates in the Netherlands and elsewhere (see Anderson \& Doyal, 2004; Bischofberger \& Vischer, 2010) on the practice of conducting research in diaspora communities and, more specifically, debates on the advantages (e.g. similar cultural understandings) and disadvantages (e.g. fear of confidentiality breaches) of matching an interviewer's ethnicity to the ethnicity of the participant, we decided it would be best if participants themselves determined whether they wanted to be ethnically matched to an interviewer. In most cases, participants were indeed matched with an interviewer sharing their ethnicity. Informed consent was obtained prior to the interview, and a monetary compensation of $€ 30$ was provided after interview completion. The interviews were held between January 2005 and May 2008 and were guided by a structured protocol of open-ended questions with follow-up probes. The protocol explored (1) what HIV means to African and Afro-Caribbean diaspora; (2) how HIV is viewed by African and 
Afro-Caribbean diaspora communities; and (3) how PLWH are viewed by African and Afro-Caribbean diaspora communities. In the interest of increasing validity and decreasing social desirability bias, both direct and indirect questioning was employed during interviews. We therefore not only asked participants to convey their own views on HIV and PLWH, we also asked them to tell us how their community views HIV and PLWH. Consistency across interviews was enhanced by providing the same training to all interviewers, by equipping all interviewers with the same structured protocol, and by evaluating transcripts to determine whether the same or similar questions were asked in all interviews.

Our sample comprised 42 HIV-positive participants, of which 16 were African, 9 Antillean, 16 Surinamese and 1 both Antillean and Surinamese, and 52 HIV-negative participants, of which 16 were African, 19 Antillean and 17 Surinamese. In both the HIV-positive and HIV-negative sample, half of the participants were men and half were women. HIV-positive participants ranged in age from 18 to 70 years with a mean age of 38.6 years $(S D=10.47)$. Twenty-seven of these participants (64.3\%) identified themselves as heterosexual and 13 $(31.0 \%)$ as gay, and data were missing for the remaining two participants. In terms of education, 23.8\% $(n=10)$ of HIV-positive participants had a low level of educational attainment, $47.6 \%(n=20)$ a moderate level of educational attainment, and $28.6 \%(n=12)$ a high level of educational attainment. In this sample, African participants originated from a number of countries including Burundi, Cameroon, the Democratic Republic of the Congo, Ghana, Kenya, Nigeria, Rwanda, South Africa, Uganda, Zambia and Zimbabwe while Antillean participants originated from the islands of Curaçao and Bonaire, and Surinamese participants from Suriname. In the HIV-negative sample, participants ranged in age from 18 to 70 years with a mean age of 34.9 years $(S D=13.88)$. Sexual orientation was not determined for this sample. Educational attainment was low for $17.3 \%(n=9)$, moderate for $46.2 \%(n=24)$, high for $34 \%(n=17)$, and data were missing for the remaining two participants $(3.8 \%)$. HIV-negative African participants originated from Angola, the Democratic Republic of the Congo, Ghana, Guinea, Kenya, Rwanda, South Africa, Sudan and Tanzania, while Antillean participants originated from Curaçao and Bonaire, and Surinamese participants from Suriname.

To enhance rigour, all interviews were recorded with a digital voice recorder and transcribed verbatim. Data were processed with QSR NVivo 2.0 (Doncaster, Australia) and analysed using a general inductive approach (Thomas, 2006) by a bilingual researcher trained in cross-cultural translation (SS). Each transcript was read thoroughly while listening to the corresponding recording to identify emerging themes and establish categories to which text fragments were assigned. As coding occurred, categories and subcategories were linked to one another. A decision trail was maintained (Polit \& Beck, 2010). All emergent categories were documented, as were changes made to the categories and the rationale for those changes. Coding continued until saturation was evident. Findings were subsequently checked with relevant stakeholders in the African, Antillean and Surinamese communities in the Netherlands (e.g. community leaders, service providers, representatives of civil society organizations, and professionals and volunteers active in the field of HIV prevention and care).

\section{RESULTS}

\section{Perceived contagiousness}

African, Antillean and Surinamese participants, both HIV-positive and HIV-negative, reported that people in their community tend to believe that HIV is easily acquired and 
transmitted through casual contact such as touching, shaking hands, sharing eating and drinking utensils, and, in some cases, simply being in the same space as PLWH. One participant said, 'People think that if you spend time with someone who has HIV, you will get it too, like if you touch that person, you'll automatically be infected' (HIV-negative Surinamese woman). Another stated, 'There are still people who believe that you can get contaminated by sharing eating utensils and drinking utensils and clothes and things like that' (HIV-negative South African woman).

The link between HIV and contagiousness was also apparent in HIV-negative community members' descriptions of PLWH. Particularly, Antillean and Surinamese participants reported that PLWH are considered 'dirty'. One participant said, '[PLWH] are talked about very negatively... That they are dirty or something' (HIV-negative Surinamese woman). Another said, 'If someone has something you don't want to get, you can almost call it dirty. No one will want to be around that person' (HIV-negative Antillean woman).

That HIV is perceived as highly contagious in African, Antillean and Surinamese communities was confirmed by HIV-positive participants: 'They think if they touch you, they'll automatically get HIV, or if they talk to you — that's what they think-or even eating from the same plate' (HIV-positive Surinamese woman). Another HIV-positive participant said, 'People are more afraid to have any kind of contact with you even though it is commonly known that people cannot get HIV through just hugging or drinking from the same glass' (HIV-positive Congolese man).

Many participants, both HIV-negative and HIV-positive, attributed high levels of perceived contagiousness and consequent fear of PLWH to ignorance, as exemplified by the following citation.

People are not aware of the virus and how you can get infected. People think that if they come in contact with that person, shake a hand, they will get it but that's not it. It's just that people don't know enough about the disease. People think that if they touch someone with HIV, they will become infected but that isn't true. I think it's ignorance. (HIV-negative Antillean woman)

Interestingly, this proclaimed lack of knowledge was not apparent among this study's HIV-negative African, Antillean and Surinamese participants. A few participants demonstrated some incorrect knowledge or lack of certainty regarding whether HIV can be transmitted through saliva but, on the whole, most were well-informed with respect to HIV transmission and prevention. Nonetheless, high levels of perceived contagiousness were reported. This suggests discordance between knowledge (e.g. HIV cannot be transmitted through casual contact) and behaviour (e.g. avoidance or increased physical distance from PLWH), and is exemplified by comments in which participants indicated that, despite knowing that they cannot acquire HIV through casual contact, they would nevertheless be 'careful' when in the presence of PLWH, 'just in case'.

If I know that someone is infected with HIV, then I think that I would be a little more distant with that person, and that is just automatic because we know that the disease is only transmitted through blood and fluids. So I think I would be a little more cautious. Somehow, there is fear in your body, I think. In my opinion, you would kind of put the handbrake on. (HIV-negative Surinamese man)

In our comparison of the communities, some differences between the communities were noted. In Antillean and Surinamese communities, the fear of contagion was predominantly related to acquiring HIV through physical contact, while in African communities, this fear also pertained to the air, perhaps because HIV and tuberculosis co-infection is prevalent in African countries. One participant stated, 'Some people are just scared of even sitting close 
to me like you are sitting right now because they have no idea. They think it could come from the air and infect you' (HIV-positive Nigerian man). Another said, 'People don't want to come near you. They don't know it is not contagious. They think it's like tuberculosis. They think it's in the air but it is not in the air' (HIV-negative Ghanaian man).

\section{Perceived severity}

High levels of perceived severity in African, Antillean and Surinamese diaspora communities were also noted. HIV was considered by many HIV-negative participants to be a 'death sentence' (HIV-negative Antillean man) and a 'killer disease' (HIV-negative Congolese woman). This belief that HIV is analogous to death was vividly described by one participant as follows.

You know that you can't get rid of it and that you'll die. You'll have it for the rest of your life and you will need to take medicine to slow it so that it doesn't go really fast but you know that the end is in sight. . .However you look at it, the end is in sight. . Your future's in the gutter, so to speak. It's not a fever for which you just take a couple of pills and in three days, you're better. You have to change your whole life, your lifestyle. You have to take medicine day and night to make it just a little easier otherwise you'll just rot away. It is horrible. (HIV-negative Surinamese man)

Evidently, the lifelong obligation to take medication was also seen by the aforementioned participant and others as a factor that contributes to the perceived severity of HIV: 'You will be on a whole lot of medication for years. You live only to take those pills' (HIV-negative Antillean woman).

HIV-positive participants indicated that they too had associated HIV with death prior to and shortly after their diagnosis, as did their families and friends. One participant said that when he was told that he had HIV, he thought he had 'come to the end of the road' (HIV-positive Nigerian man). Another said, 'I thought, "I'm going to go home, clean my whole house and prepare myself for death" (HIV-positive Antillean woman). Yet another participant spoke of how her family looked at her as if she were a 'time bomb' that could 'drop dead' at any moment (HIV-positive Rwandan woman). Fortunately, many PLWH conveyed that they themselves and most of the people close to them have since come to realize that HIV is not a death sentence and that it is possible to live a healthy life with HIV. However, among those who are not close to a PLWH, the idea that HIV is a fatal disease appears to persist, despite the acknowledgement of anti-retroviral medication by approximately half of the HIV-negative participants.

Another related belief reinforcing the belief that HIV is very severe is that PLWH are 'skinny'. Participants from all three ethnic groups indicated that if someone loses weight and becomes thin, people will assume that that person has HIV: 'Even my own junior brother, he used to have one of my friends and then tell me, "That man is so pale, so slender, I suspect he has HIV"' (HIV-positive Cameroonian woman). Another HIV-positive participant exemplified this notion that weight and HIV-status are connected when she told the interviewer about how her mother in Suriname was concerned about her being ill and was comforted over the telephone by the following words: 'Mama, if you could see me, you'd see that I am 100 kilograms' (HIV-positive Surinamese woman). Clearly, this notion that HIV can be seen on a person is present in African, Antillean and Surinamese communities and is linked to beliefs regarding the course and severity of the condition. In essence, it exemplifies beliefs that PLWH are so ill that they wither away and die: 'It just eats you all through and at the end of the day it just leaves you an empty frame-nothing else' (HIV-negative Kenyan woman). 
The degree to which HIV was perceived as a very severe condition did not appear to vary between the ethnic communities. In all three ethnic groups, the majority of participants contended that HIV is a very serious disease. What was observed was that, in general, the HIV-negative participants tended to sketch a much bleaker and severe picture of life as a person with HIV than PLWH did.

\section{Personal responsibility}

Numerous HIV-negative participants indicated that PLWH are often thought to have acquired HIV through irresponsible, preventable action such as unprotected sex. As such, PLWH are seen as blameworthy for their infection: 'They brought it on themselves' (HIV-negative Kenyan man). One Antillean participant contended that, 'Getting HIV is not an accident that just happens to you. It's not like "Oh poor you, you got HIV." No, it is simply your own responsibility' (HIV-negative Antillean woman). Another claimed that 'Surinamese people tend to think: it's your own fault and, in essence, that's true' (HIV-negative Surinamese man).

A few HIV-positive participants indicated that they indeed felt responsible for their HIV infection and see, or have seen, their infection as punishment for bad behaviour: 'I first thought that this was punishment-punishment from God, you know. I deserved it because of, you know, the lifestyle I had' (HIV-positive Surinamese man).

In fact, especially among Surinamese and African participants, HIV is often seen as punishment from ancestors or God for poor or immoral behaviour.

The way that people look at $[\mathrm{PLWH}]$ is like you are really immoral. That is why you get the disease... The first thing that comes to people's mind is that you must have been immoral and that is why you have it. (HIV-negative Kenyan woman)

You often hear: 'It's a curse. You were bad.' People think that it has something to do with the spiritual world and those kinds of things. . Winti things and then they say, "Your ancestors are angry with you and have cursed you." (HIV-negative Surinamese man)

The data further suggest that because PLWH are held personally responsible for their infection, they are often met with less compassion and empathy than people who suffer from a condition other than HIV: 'Why is that if someone loses a leg, people understand but if someone has HIV, they don't?' (HIV-positive Surinamese woman).

If someone gets cancer, then he gets compassion. If someone gets HIV, he doesn't get that easily. It's more a fear reaction and then, 'Oh shit, you're going to die.' ... I think that only haemophilia patients that have gotten HIV through a blood transfusion get the same kind of compassion or understanding. (HIV-positive Antillean man)

With respect to differences between the ethnic communities, we found that the role of personal responsibility as a contributing factor to stigmatization was less present, but surely not absent, in Antillean communities compared with Surinamese and African communities.

\section{Associations with norm-violating behaviours}

Since the beginning of the epidemic, HIV has been associated with behaviours that are considered norm violating or socially unacceptable. Our study found HIV to be associated with promiscuity, commercial sex work and homosexuality. 
Promiscuity and commercial sex work. Participants from all three ethnic communities reported that most people in their community associate HIV with being 'loose' or 'easy'.

People who carry the disease: To us, they are loose - people who just do whatever and go to bed with whoever and aren't careful about things like using a condom or something. They just dive into bed with anyone and that is looked down upon. (HIV-negative Antillean woman)

Participants also reported that this association between HIV and promiscuity most often pertains to women. Women 'tend to be blamed to be the promiscuous; it falls more on the women' (HIV-negative Kenyan woman). The following excerpt from an interview illustrates this well.

If a girl has lots of boyfriends and those kinds of things, then she automatically has AIDS. . .only because she is sexually active. They don't consider that maybe she just likes it and she does it safely. No, she is automatically a whore and she automatically has AIDS. For boys, that's [promiscuity] cool and manly. (HIV-negative Antillean woman)

In some cases, participants referred to commercial sex work as a specific form of promiscuity. This association was particular apparent among African participants: 'Sometimes they think, "Oh, she was a prostitute"... they will treat [her] like she is a hooker' (HIV-negative Kenyan woman). This was confirmed by African PLWH: 'People think when you are HIV-positive- they label you as prostitute' (HIV-positive Rwandan woman).

When the association between promiscuity and HIV pertained to men, infidelity was frequently mentioned. In fact, among the Antillean participants, comments on infidelity pertained exclusively to men and, interestingly, were made exclusively by women, thus reflecting the structure of romantic relationships in Antillean communities where infidelity on the part of men is considered normal but not appreciated by women.

Logically, when participants spoke of the association between HIV and promiscuity, they also often mentioned an attribution of blame. One participant said, 'There are still people who believe that they asked for it because they had many men or many women, because they are loose' (HIV-negative South African woman). Another participant described how people think about PLWH as follows.

[People say] "He's been/she's been sleeping around. You see? This is what you get!" It is not like it can happen by mistake. They are like "You looked for it.". . She has brought this disease to herself. She was promiscuous herself. She is the one who brought the disease. (HIV-negative Kenyan woman)

Unsurprisingly, HIV-positive participants were keenly aware that HIV is associated with promiscuity, commercial sex work and infidelity and that these behaviours also yield blame. This was exemplified by the fact that a number of HIV-positive participants explicitly, but without solicitation, defended their fidelity and emphasized that they did not acquire HIV through irresponsible behaviour: 'I didn't go around screwing everyone and anyone' (HIV-positive Surinamese woman).

They see you as a whore and because you are a whore, you got the disease, and because of that, they don't want anything to do with you because you are a whore. "You sleep with whoever whenever"- - that's how they think but it's not true. It's not true but they think that. (HIV-positive Antillean woman)

With respect to differences between the ethnic communities, we observed that the association between HIV and promiscuity was present in all ethnic groups but more common in African communities than in Antillean and Surinamese communities. 
Homosexuality. The belief that HIV is a 'gay disease' was very present and explicit among Antillean and Surinamese participants but not among African participants. Many HIV-negative Surinamese and Antillean participants made some reference to homosexuality when asked what beliefs are linked to HIV: 'I think of gays that have the virus. Most people in my culture say that it is the gays that have it' (HIV-negative Surinamese woman). Another participant said, 'Usually, gay men get it. That's kind of the idea-that only gay men have HIV' (HIV-negative Antillean woman). This belief was confirmed by PLWH: 'Either way, people think it is a gay disease' (HIV-positive Antillean man).

Once again, attributions of personal responsibility were observed. Men who had sex with men were considered blameworthy for their HIV infection.

They say, well, that is more a gay thing — man and man — and that is not allowed and that is not good. You have some families that accept it but not many. From the time you are a kid, you know it is not good. Many Surinamese people think that it is not from God and that is why you get the disease. (HIV-positive Surinamese man)

\section{Cultural taboos}

Many of the participants from African, Antillean and Surinamese communities contended that the beliefs that reinforce stigmatization of PLWH (i.e. HIV is highly contagious, very severe, acquired through volitional behaviour for which one can be held personally responsible, and associated with promiscuity, commercial sex work and homosexuality) are exacerbated and perpetuated by silence, denial and taboo within their communities. One participant said, 'In my community, some people don't want to talk about HIV . . .I know, [in] my community, when I start to talk about HIV, nobody want[s] to talk about this' (HIV-negative Guinean man). Another participant stated, 'People often think that you can get HIV just by touching. They think that because they don't ever talk about it [HIV]' (HIV-positive Antillean man).

The cultural taboo on talking about HIV in African, Antillean and Surinamese communities also appears to be exacerbated by taboos on talking about all things related to sexuality in African, Antillean and Surinamese culture.

You know what it is? The way in which you get infected is sexual. Of course you can get it through injection needles but [the Antillean community] assume[s] that it is always from sex and, among Antilleans, talking about sex is a taboo, and so you have this disease that you get through sex and the taboo only gets bigger. (HIV-negative Antillean woman)

When you think about HIV - in fact, I am talking about it right now because you are asking me those questions but it is a very silent disease. We actually don't even use the word HIV. It is coming more and more to light because of the fact that when you have this disease where we have given it various names because of the stigma surrounding the disease and the fact that it is not discussed. It is such a taboo to talk about HIV/AIDS and that is because it is a sexually transmitted disease. (HIV-negative Kenyan woman)

In Antillean and Surinamese communities, the taboo on talking about sexuality is even greater when it pertains to homosexuality.

I was thinking, 'Why is [HIV] so stigmatized?' It has to do with the whole homosexuality thing that, on its own, is a stigma and a taboo. In some cultures, it's starting to come out a bit but it is not how it should be....so [stigma] is the result of that. So you are gay and you are also HIV-positive-you definitely can't talk about that. (HIV-positive Antillean and Surinamese man) 
In short, in African, Antillean and Surinamese communities, myths and beliefs about HIV and PLWH that contribute to HIV-related stigma are upheld by cultural taboos on talking about HIV, sexuality and, in Antillean and Surinamese communities, also homosexuality. On a positive note, most participants did claim that the taboo in their ethnic communities in the Netherlands was less than the taboo in their home countries. Nonetheless, cultural taboos were considered to reinforce beliefs that promote the stigmatization of PLWH.

\section{DISCUSSION}

This study is, to our knowledge, the first to comprehensively document the beliefs that contribute to HIV-related stigma in African and Afro-Caribbean diaspora communities in the Netherlands and the cultural context of these beliefs. The findings suggest that, on the whole, the beliefs that have been found to contribute to the stigmatization of PLWH in Europe and North America also are held by members of Sub-Saharan African and Caribbean diaspora communities.

The findings show that, in African, Dutch Antillean and Surinamese diaspora communities, the belief that HIV is highly contagious and that casual social contact can pose a risk for HIV infection persists despite adequate knowledge regarding HIV transmission. This discrepancy has previously been found in African studies (Maman et al., 2009; Ogden \& Nyblade, 2005), and studies conducted in North America have also found that people have aversions to casual contact with PLWH despite apparent awareness of how HIV is actually transmitted (Pryor et al., 1999; Rozin, Markwith, \& Nemeroff, 1992). Research has shown that people often manifest an automatic and immediate aversion to stigmatized persons that can be followed by a controlled and thoughtful reaction. The controlled and thoughtful reaction is contingent upon adequate knowledge about HIV transmission, time to consider one's reaction and the motivation not to stigmatize (Pryor, Reeder, Yeadon, \& Hesson-McLnnis, 2004). Our study shows that when people are unsure about the fine details of HIV transmission, they tend to err on the side of caution and avoid PLWH, thus suggesting that interventions aimed at the reduction of HIV-related stigma should seek to reduce this lack of certainty by providing information on how HIV is not transmitted in addition to building skills pertaining to social interactions with PLWH (Bos, Schaalma, \& Pryor, 2008; Brown et al., 2003; Ogden \& Nyblade, 2005).

The second belief contributing to HIV-related stigma in African and Afro-Caribbean communities is the belief that HIV is a very severe disease. Participants frequently associated HIV with death and wasting. This association is not surprising given that many members of diaspora communities originate from countries where highly active anti-retroviral therapy (HAART) has, until recently, been or currently remains either unavailable or difficult to access. HIV-related stigma reduction interventions should therefore aim to increase awareness of HAART in diaspora communities and convey, through information and personal contact with PLWH, that HIV is, at least in the Europe and North America, a chronic condition and that PLWH can lead long and healthy lives with HIV (Bos et al., 2008; Ogden \& Nyblade, 2005).

The third belief is the belief that PLWH are personally responsible for their HIV infection. In our study, we found that attributions of blame are common in African, Antillean and Surinamese diaspora communities and that HIV is frequently considered due justice for immoral or irresponsible behaviour, thus yielding less compassion for PLWH than 
for people with other medical conditions. In some cases, the punishment is considered to come from God; in others, it comes from ancestors. Attributions of blame have previously been found in a quantitative study conducted by Visser and colleagues (2006) in South Africa. In their study, $61 \%$ of the participants considered PLWH to be of poor moral character, $22 \%$ considered HIV to be punishment for bad behaviour and $26 \%$ blamed PLWH for contracting HIV. Interventions aiming to counter the effect of attributions of personal responsibility can focus on generating empathy for PLWH through, for example, repeated personal and/or vicarious contact with PLWH (Bos et al., 2008; Brown et al., 2003; Herek \& Capitanio, 1997). Such contact not only has the potential to increase awareness of HIV and decrease fear reactions to PLWH; it has also been established as an effective means of inducing sympathy and compassion for stigmatized individuals and subsequent stigma reduction (Bos et al., 2008; Brown \& Hewstone, 2005; Norman et al., 2009; Pettigrew \& Tropp, 2006; Visser et al., 2006).

The fourth belief contributing to HIV-related stigma is the belief that PLWH have acquired HIV because they engaged in apparently norm-violating behaviour. Our findings suggest that these associations can differ from one culture to another. For example, in our study, HIV was associated with homosexuality only in Afro-Caribbean communities and not in African communities. In African communities, the association with commercial sex work appeared stronger than in Afro-Caribbean communities. In all three ethnic groups, HIV was associated with promiscuity but, in Antillean communities, promiscuity was, according to female participants, analogous to male infidelity. Also, unlike studies conducted in Europe and North America, in our study, HIV was not associated with intravenous drug use. This suggests that the associations made are indeed impacted by culture and the nature of the epidemic in the regions from which diaspora originate. Changing negative attitudes toward promiscuity, commercial sex work and homosexuality is difficult as such attitudes are often deeply entrenched in one's culture. HIV-related stigma reduction interventions can seek to provide stereotype-inconsistent information about HIV and PLWH and offer a safe environment in which community members can discuss their stigma-related values and beliefs (Bos et al., 2008; Nyblade et al., 2003; Ogden \& Nyblade, 2005), but more is needed. Societal and community structures as well as cultural beliefs that judge promiscuous behaviour, reinforce negativity toward commercial sex work and oppress men who have sex with men must be addressed (Kalichman \& Simbayi, 2003; Parker \& Aggleton, 2003). This requires public commitment from all sectors of government as well as community leaders and the media (Visser et al., 2006).

An additional finding of our study is that cultural taboos on talking about HIV and sexuality in African, Antillean and Surinamese communities exacerbates the aforementioned beliefs. In Afro-Caribbean communities, the taboo on sexuality extends also to homosexuality. The contributing role of taboo to HIV-related stigma has previously been noted by studies conducted in Sub-Saharan Africa (Campbell, Foulis, Maimane, \& Sibiya, 2005; Roura et al., 2008) and in studies with African and Caribbean diaspora (Burns et al., 2007; Dodds, 2006; Gardezi et al., 2008). Taboos can perpetuate myths regarding HIV transmission and severity while reinforcing attributions of blame and norm violation. Breaking cultural taboos on HIV and sexuality is thus imperative if stigmatization toward PLWH is to be reduced. Public disclosure to one's community on the part PLWH can break taboos and thereby contribute to stigma reduction but must be applied cautiously as such disclosure can have both positive and negative consequences (Paxton, 2002; Stutterheim et al., 2009; Stutterheim Bos, Pryor, et al., 2011). It is therefore important that 
PLWH who want to contribute to breaking taboos and reducing stigma be empowered and adequately equipped to deal with negative reactions. Interventions that support PLWH and train them in how to best disclose their status and how to cope with potential negative reactions must precede interventions that utilize PLWH as public spokesmen to break taboos and reduce stigma (Bos et al., 2008; Brown et al., 2003).

Our findings are in line with previous research conducted with African and Afro-Caribbean diaspora communities (Anderson et al., 2008; Burns et al., 2007; Dodds et al., 2004; Gardezi et al., 2008; Kinniburgh, Scott, Gottlieb, \& Power, 2001). What our study adds to previous research findings is not only a description of the current situation in the Netherlandssomething that has not previously been documented - and the triangulation of data across HIV-positive and HIV-negative individuals in African and Afro-Caribbean diaspora, but also a specific focus on, and more comprehensive delineation of, the beliefs contributing to HIV-related stigma in diaspora communities. We explicitly investigated beliefs, while other studies tended to focus on experiences with stigmatization and reported underlying beliefs only incidentally. Nonetheless, our findings confirm incidentally reported beliefs in other studies of African and Afro-Caribbean diaspora. For example, in their study of stigma and discrimination experienced by African people with HIV in the UK, Dodds and colleagues (2004) reported that HIV carries associations with commercial sex work and promiscuity, that HIV is heavily laden with notions of immorality and that there is a connection between HIV and death. Burns et al. (2007) also mentioned how HIV is equated with death in their study of why African migrants in the UK delay or avoid use of health and social care services. They additionally reported that because HIV is a sexually transmitted infection, it carries connotations about personal character and an implication of blame, which appears analogous to our finding regarding personal responsibility. Burns and colleagues also reported a lack of openness about HIV in these communities, as did Kinniburgh and colleagues (2001) in their study of discrimination against Black and ethnic minority communities in the UK. These findings are in line with our finding that HIV is a taboo topic in African diaspora communities. Other analogous results have been yielded by a Canadian study of African and Caribbean communities' experiences of, and responses to, HIV (Gardezi et al., 2008). In their study, Gardezi and colleagues found that HIV is associated with death and thought to be a punishment for immoral behaviour. They too found that, among Caribbean participants, HIV is associated with homosexuality. Furthermore, they reported on emotional stoicism claiming that sex, sexuality and health issues are rarely discussed in these communities. This too corresponds with our finding that sexuality is a taboo topic in these communities. Lastly, a study on HIV-related stigma and discrimination among Caribbean people in the UK conducted by Anderson and colleagues (2008) reported that HIV-related stigma is attributable, in part, to a fear of contamination, that HIV is associated with both promiscuity and homosexuality and that HIV is considered the result of immoral behaviour. They too claimed that taboo on talking about sex contributes to HIV-related stigma. Evidently, the aforementioned studies have all, to some extent but in less detail, yielded similar findings to our study.

Our study has a number of strengths but also some limitations. Strengths include the inductive nature and 'thick' description of the data, the triangulation of data across people with and without HIV, the use of a voice recorder and verbatim transcriptions, the maintenance of a decision trail and the fact that findings were checked with stakeholders. A limitation of our study was the fact that we failed to consider how long participants had been in the Netherlands and the degree to which living in the Netherlands affected their beliefs and their connection to diaspora communities. Future research should consider 
participants' time since immigration when investigating matters pertaining to diaspora communities. We also suggest that future research explore the degree to which HIV-related stigma is impacted by relocation from one's home country to a country in which one is diaspora and the actual differences in HIV-related stigma between one's home country and one's diaspora community. Lastly, we recommend investigating similarities and differences between African and Afro-Caribbean diaspora communities and communities comprising people indigenous to Europe or North America.

In their totality, our findings point to the need for community-based interventions in African, Dutch Antillean and Surinamese diaspora communities that are geared to changing beliefs regarding contagiousness, severity and personal responsibility and reducing associations between HIV and norm-violating behaviour such as promiscuity, commercial sex work and, in Afro-Caribbean communities, also homosexuality. Interventions should also seek to break cultural taboos on HIV and sexuality. In order to be effective, these community-based interventions must be rooted in theory and evidence and involve both HIV-negative and HIV-positive community members throughout all phases of intervention development, implementation and evaluation (Bos et al., 2008; Brown et al., 2003). In the absence of such interventions, HIV-related stigma is likely to persist and have negative consequences for not only PLWH but also their communities.

\section{ACKNOWLEDGEMENTS}

The authors thank the participants, the Dutch AIDS Fonds and Abbott (grants 2006092, 7004), the Dutch HIV Association, Humanitas, the Professional Organization of HIV Consultants, Community Health Services in Amsterdam, Groningen and Rotterdam and the following people: Gerjo Kok, Jeannine Nellen, Jan Prins, Evert van Veen, Fetzen de Groot, Juan Walter, Maartje Liebregts, Mariette Hamers, Onno de Zwart, Ronald Brands, Stephan Cremer, Chantal Rumanzi, Dudly Tijn-a-Kwie, Elizabeth Njeru, Emmy Markelo, Erik Beune, Germain Ackermans, Indira Snip, Juan Walter, Mikel Haman, Mirte Wibaut, Nadia Mirjals, Pamela Matinde, Rubelto Baker, Urmy Macnack, Anne van Middelaar, Carolien van Wagenberg, Danielle Pool, Joyce van Leendert, Roy van Veldhuizen, Sanne van Lieshout and Simone Heijnen.

\section{REFERENCES}

Anderson, J., \& Doyal, L. (2004). Women from Africa living with HIV in London: A descriptive study. AIDS Care, 16(1), 95-105.

Anderson, M., Elam, G., Gerver, S., Solarin, I., Fenton, K., \& Easterbrook, P. (2008). HIV/ AIDS-related stigma and discrimination: Accounts of HIV-positive Caribbean people in the United Kingdom. Social Science and Medicine, 67(5), 790-798.

Bischofberger, I., \& Vischer, L. R. (2010). Interviewing Sub-Saharan migrants in Switzerland about HIV/AIDS: Critical reflections on the interview process. Journal of Transcultural Nursing, 21(1), 23-28.

Bos, A. E. R., Dijker, A. J. M., \& Koomen, W. (2007). Sex differences in emotional and behavioral responses to HIV+ individuals' expression of distress. Psychology \& Health, 22(4), 493-511.

Bos, A. E. R., Kok, G., \& Dijker, A. J. (2001). Public reactions to people with HIV/AIDS in the Netherlands. AIDS Education and Prevention, 13(3), 219-228. 
Bos, A. E. R., Schaalma, H. P., \& Pryor, J. B. (2008). Reducing AIDS-related stigma in developing countries: The importance of theory- and evidence-based interventions. Psychology, Health \& Medicine, 13(4), 450-460.

Brown, R., \& Hewstone, M. (2005). An integrative theory of intergroup contact. In M. P. Zanna (Ed.), Advances in Experimental Social Psychology (Vol. 37, pp. 255-343). San Diego, CA: Elsevier Academic Press.

Brown, L., Macintyre, K., \& Trujillo, L. (2003). Interventions to reduce HIV/AIDS stigma: What have we learned? AIDS Education and Prevention, 15(1), 49-69.

Burns, F. M., Imrie, J. Y., Nazroo, J., Johnson, A. M., \& Fenton, K. A. (2007). Why the(y) wait? Key informant understandings of factors contributing to late presentation and poor utilization of HIV health and social care services by African migrants in Britain. AIDS Care, 19(1), 102-108.

Campbell, C., \& Deacon, H. (2006). Unravelling the contexts of stigma: From internalisation to resistance to change. Journal of Community \& Applied Social Psychology, 16(6), 411-417.

Campbell, C., Foulis, C. A., Maimane, S., \& Sibiya, Z. (2005). "I have an evil child at my house": Stigma and HIV/AIDS management in a South African community. American Journal of Public Health, 95(5), 808-815.

Carr, R. L. (2004). Stigmas, coping and the impact of gender on patterns of social ostracism: A qualitative study with HIV+ Jamaicans. Kingston, Jamaica: University of the West Indies.

Crocker, J., Major, B., \& Steele, C. (1998). Social stigma. In D. T. Gilbert, S. T. Fiske \& G. Lindzey (Eds.), The handbook of social psychology (4th ed., Vol. 1 \& 2, pp. 504-553). New York, NY: McGraw-Hill.

Deacon, H. (2006). Towards a sustainable theory of health-related stigma: Lessons from the HIV/ AIDS literature. Journal of Community \& Applied Social Psychology, 16(6), 418-425.

Dijker, A. J., \& Koomen, W. (2003). Extending Weiner's attribution-emotion model of stigmatization of ill persons. Basic and Applied Social Psychology, 25(1), 51-68.

Dodds, C. (2006). HIV-related stigma in England: Experiences of gay men and heterosexual African migrants living with HIV. Journal of Community \& Applied Social Psychology, 16(6), 472-480.

Dodds, C., Keogh, P., Chime, O., Haruperi, T., Nabulya, B., SSanya SSeruma, W., \& Weatherburn, P. (2004). Outsider status: Stigma and discrimination experienced by gay men and African people with $H I V$. London: Sigma Research.

Erwin, J., Morgan, M., Britten, N., Gray, K., \& Peters, B. (2002). Pathways to HIV testing and care by black African and white patients in London. Sexually Transmitted Infections, 78(1), 37-39.

Gardezi, F., Calzavara, L., Husbands, W., Tharao, W., Lawson, E., Myers, T.,...Adebajo, S. (2008). Experiences of and responses to HIV among African and Caribbean communities in Toronto, Canada. AIDS Care, 20(6), 718-725.

Genberg, B. L., Hlavka, Z., Konda, K. A., Maman, S., Chariyalertsak, S., Chingono, A.,...Celentano, D. (2009). A comparison of HIV/AIDS-related stigma in four countries: Negative attitudes and perceived acts of discrimination towards people living with HIV/AIDS. Social Science and Medicine, 68(12), 2279-2287.

Goffman, I. (1963). Stigma: Notes on the management of spoiled identity. Eaglewood Cliffs, NJ: Prentice-Hall.

Greeff, M., Phetlhu, R., Makoae, L. N., Dlamini, P. S., Holzemer, W. L., Naidoo, J. R.,...Chirwa, M. (2008). Disclosure of HIV status: Experiences and perceptions of persons living with HIV/AIDS and nurses involved in their care in Africa. Qualitative Health Research, 18(3), 311-324.

Herek, G. M. (1999). AIDS and stigma. American Behavioral Scientist, 42(7), 1106-1116.

Herek, G. M., \& Capitanio, J. P. (1997). AIDS stigma and contact with persons with AIDS: Effects of direct and vicarious contact. Journal of Applied Social Psychology, 27(1), 1-36.

Jones, E., Farina, A., Hastorf, A., Markus, H., Miller, D., \& Scott, R. (1984). Social stigma: The psychology of marked relationships. New York, NY: W.H. Freeman.

Kalichman, S. C., \& Simbayi, L. C. (2003). HIV testing attitudes, AIDS stigma, and voluntary HIV counselling and testing in a black township in Cape Town, South Africa. Sexually Transmitted Infections, 79(6), 442-447.

Kalichman, S. C., \& Simbayi, L. (2004). Traditional beliefs about the cause of AIDS and AIDS-related stigma in South Africa. AIDS Care, 16(5), 572-580.

Kinniburgh, J., Scott, P., Gottlieb, M., \& Power, L. (2001). Prejudice, discrimination and HIV: A report. London: Terrence Higgins Trust. 
Malcolm, A., Aggleton, P., Bronfman, M., Galvão, J., Mane, P., \& Verral, J. (1998). HIV-related stigmatization and discrimination: Its forms and contexts. Critical Public Health, 8(4), 347-370.

Maman, S., Abler, L., Parker, L., Lane, T., Chirowodza, A., Ntogwisangu, J.,...Fritz, K. (2009). A comparison of HIV stigma and discrimination in five international sites: The influence of care and treatment resources in high prevalence settings. Social Science and Medicine, 68(12), 2271-2278.

Mills, E. A. (2006). From the physical self to the social body: Expressions and effects of HIV-related stigma in South Africa. Journal of Community \& Applied Social Psychology, 16(6), 498-503.

Norman, L. R., Abreu, S., Candelaria, E., \& Sala, A. (2009). The effect of sympathy on discriminatory attitudes toward persons living with HIV/AIDS in Puerto Rico: A hierarchical analysis of women living in public housing. AIDS Care, 21(2), 140-149.

Nyblade, L., Pande, R., Mathur, S., MacQuarrie, K., \& Kidd, R. (2003). Disentangling HIV and AIDS stigma in Ethiopia, Tanzania and Zambia. Washington, DC: International Center for Research on Women.

Ogden, J., \& Nyblade, L. (2005). Common at its core: HIV-related stigma across contexts. Washington, DC: International Center for Research on Women (ICRW).

Parker, R., \& Aggleton, P. (2003). HIV and AIDS-related stigma and discrimination: A conceptual framework and implications for action. Social Science and Medicine, 57(1), 13-24.

Paxton, S. (2002). The paradox of public HIV disclosure. AIDS Care, 14(4), 559-567.

Pettigrew, T. F., \& Tropp, L. R. (2006). A meta-analytic test of intergroup contact theory. Journal of Personality and Social Psychology, 90(5), 751-783.

Polit, D. F., \& Beck, C. T. (2010). Essentials of nursing research. Philadelphia, PA: Wolters Kluwer Lippincott Williams \& Wilkins.

Pryor, J. B., Reeder, G. D., \& Landau, S. (1999). A social-psychological analysis of HIV-related stigma: A two-factor theory. American Behavioral Scientist, 42(7), 1193-1211.

Pryor, J. B., Reeder, G. D., Yeadon, C., \& Hesson-McLnnis, M. (2004). A dual-process model of reactions to perceived stigma. Journal of Personality and Social Psychology, 87(4), 436-452.

Reidpath, D. D., \& Chan, K. Y. (2005). A method for the quantitative analysis of the layering of HIV-related stigma. AIDS Care, 17(4), 425-432.

Roura, M., Urassa, M., Busza, J., Mbata, D., Wringe, A., \& Zaba, B. (2008). Scaling up stigma? The effects of antiretroviral roll-out on stigma and HIV testing. Early evidence from rural Tanzania. Sexually Transmitted Infections, 85(4), 308-312.

Rozin, P., Markwith, M., \& Nemeroff, C. (1992). Magical contagion beliefs and fear of AIDS. Journal of Applied Social Psychology, 22(14), 1081-1092.

Shiripinda, I., \& van Eerdewijk, A. (2008). Facing HIV in the Netherlands: Lived experiences of migrants living with HIV. Utrecht, the Netherlands: Pharos/SOA AIDS.

Stutterheim, S. E., Bos, A. E. R., Pryor, J. B., Brands, R., Liebregts, M., \& Schaalma, H. P. (2011). Psychological and social correlates of HIV status disclosure: The significance of stigma visibility. AIDS Education and Prevention, 23(4), 382-392.

Stutterheim, S. E., Bos, A. E. R., Shiripinda, I., de Bruin, M., Pryor, J. B., \& Schaalma, H. P. (2011). HIV-related stigma in African and Afro-Caribbean communities in the Netherlands: Manifestations, consequences and coping. Psychology \& Health.

Stutterheim, S. E., Pryor, J. B., Bos, A. E., Hoogendijk, R., Muris, P., \& Schaalma, H. P. (2009). HIV-related stigma and psychological distress: The harmful effects of specific stigma manifestations in various social settings. AIDS, 23(17), 2353-2357.

Thomas, D. R. (2006). A general inductive approach for qualitative data analysis. American Journal of Evaluation, 27(2), 237-246.

UNAIDS. (2008). 2008 Report on the global AIDS epidemic (No. 08.25E/JC1510E). Geneva, Switzerland: UNAIDS.

Varas-Diaz, N., Serrano-Garcia, I., \& Toro-Alfonso, J. (2005). AIDS-related stigma and social interaction: Puerto Ricans living with HIV/AIDS. Qualitative Health Research, 15(2), 169-187.

Vermeer, W., Bos, A. E., Mbwambo, J., Kaaya, S., \& Schaalma, H. P. (2009). Social and cognitive variables predicting voluntary HIV counseling and testing among Tanzanian medical students. Patient Education and Counseling, 75(1), 135-140.

Visser, M. J., Makin, J. D., \& Lehobye, K. (2006). Stigmatizing attitudes of the community towards people living with HIV/AIDS. Journal of Community \& Applied Social Psychology, 16(1), 42-58. 